\title{
Commentary: Polymer prosthetic heart valves-A new era
}

\author{
Ming-Sing Si, MD
}

\author{
From the Section of Pediatric Cardiovascular Surgery, Department of Cardiac Surgery, University of Michigan, \\ Ann Arbor, Mich. \\ Disclosures: Author has nothing to disclose with regard to commercial support. \\ Received for publication Feb 3, 2019; accepted for publication Feb 4, 2019. \\ Address for reprints: Ming-Sing Si, MD, 11-735 C.S. Mott Children's Hospital, SPC 4204, 1540 E Hospital Dr, \\ Ann Arbor, MI, 48109-4204 (E-mail: mingsing@umich.edu). \\ J Thorac Cardiovasc Surg 2019;157:1817-8 \\ $0022-5223 / \$ 36.00$ \\ Copyright (C) 2019 Published by Elsevier Inc. on behalf of The American Association for Thoracic Surgery \\ https://doi.org/10.1016/j.jtcvs.2019.02.014
}

As with most synthetic or xenogeneic implanted devices, prosthetic heart valves have the shortcomings of degeneration or failure, pannus formation, and thrombosis. ${ }^{1}$ Allogeneic valves, because of their nonvital and perhaps immunogenic state, are also prone to eventual degeneration and calcification. The pulmonary autograft in the aortic position is a living valve that lacks the shortcomings of prosthetic valves but has a risk of dilating with time. ${ }^{2}$ The ideal prosthetic valve would have the same functional abilities and characteristics as a native, living valve, with the ability to grow, remodel, regenerate, resist infection, and prevent thrombosis. At the very minimum, a prosthetic heart valve must never have a sudden, catastrophic failure.

A tissue-engineered valve would have the theoretic potential to function as a normal valve. Two main strategies to create a tissue-engineered valve are (1) creation of cellularized constructs in vitro, which may need further pulsatile conditioning before implantation, and (2) in vivo cellularization of a decellularized, bioabsorbable synthetic (or natural) polymer scaffold after implantation.

The recent study by Coyan and colleagues ${ }^{4}$ published in this issue of the Journal describes a pilot, short-term evaluation of a scaffold-based polycarbonate urethane urea tissue engineered heart valve. What is unique about this valve is that it is designed to mimic native valve microstructure and was constructed with a unique electrospinning process described in previous reports. ${ }^{5,6}$ In this study, Coyan and colleagues ${ }^{4}$ housed the valve in a magnesium stent frame and implanted it in the pulmonary position in 5 pigs for 12 hours ( 1 had been killed earlier for an unrecognized tricuspid valve defect). Outcomes that were followed were periodic echocardiograms for valve function and detailed examination of the explanted valve for structural integrity and evaluation for microscopic thrombosis. Coyan and colleagues ${ }^{4}$ found that the valve was competent throughout the entire study period and had a mild gradient. There was no evidence of structural deterioration or thrombosis on the valve leaflets. Fibrin deposits were, however, found on a minority of the magnesium stent frames. Coyan and colleagues ${ }^{4}$ concluded that their valve provided

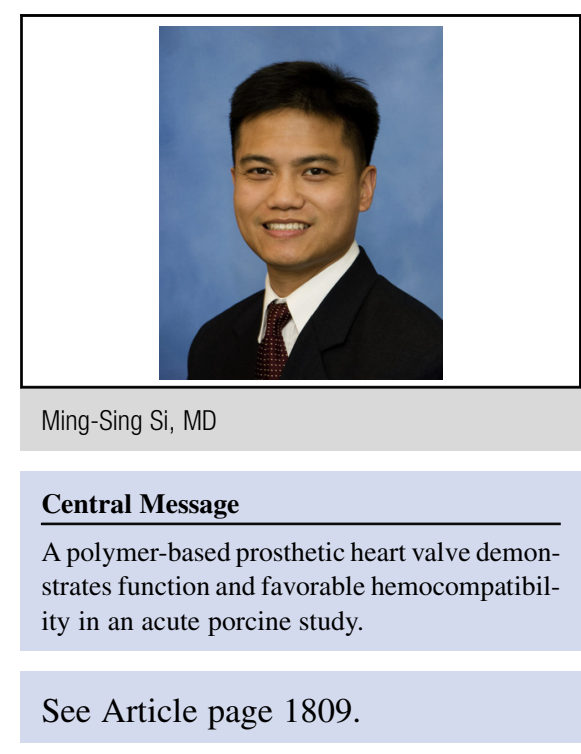

function in the early setting but requires additional optimization of the stent frame as well as a larger and longer implant study.

This study is important because it belongs to an effort to create a potentially new class of prosthetic valves composed of synthetic polymer leaflets. Assuming that these new valves pass the initial muster of biomechanical strength that prevents catastrophic failure, the immediate advantages of these valves relative to current valve replacement options are (1) the ability to manufacture valve leaflets in bespoke, complex 3-dimensional geometry and (2) the tunable chemistry to obtain the desired biomechanical properties, biocompatibility, hemocompatibility, and degradation kinetics. The Xplore-1 and 2 trials of a polymer-based right ventricle-to-pulmonary artery conduit evaluate the seminal member of this exciting class of prosthetic valves (NCT02700100 and NCT03022708 at www.clinicaltrials.gov). It is anticipated that initial failures may be encountered in this field, however, because optimization of the polymer chemistry to achieve all the desired valve properties in humans is extraordinarily complex and may require a more global, systems-level approach rather than a preferred-candidates approach. ${ }^{7}$ Furthermore, in this new class of prosthetic valves, it is certainly conceivable that individual leaflets can be fabricated for single or multiple leaflet replacement, as in the Ozaki procedure, ${ }^{8}$ and therefore would not need the additional structure to house the valve for surgical implantation. 
The findings of Coyan and colleagues ${ }^{4}$ require additional longer-term studies to confirm mechanical stability, in vivo cellularization, and controlled degradation. Furthermore, the degradation products must be nontoxic. Nonetheless, our field is entering a new, exciting era in heart valve replacement technology, one that has the potential to positively impact millions of lives.

\section{References}

1. Vesey JM, Otto CM. Complications of prosthetic heart valves. Curr Cardiol Rep. 2004;6:106-11.

2. David TE, Omran A, Ivanov J, Armstrong S, de Sa MP, Sonnenberg B, et al. Dilation of the pulmonary autograft after the Ross procedure. J Thorac Cardiovasc Surg. 2000;119:210-20.
3. Motta SE, Lintas V, Fioretta ES, Hoerstrup SP, Emmert MY. Off-the-shelf tissue engineered heart valves for in situ regeneration: current state, challenges and future directions. Expert Rev Med Devices. 2018;15:35-45.

4. Coyan GN, D'Amore A, Matsumura Y, Pedersen DD, Luketich SK, Shanov V, et al. In vivo functional assessment of a novel degradable metal and elastomeric scaffold-based tissue engineered heart valve. J Thorac Cardiovasc Surg. 2019; 157:1809-16.

5. D'Amore A, Luketich SK, Raffa GM, Olia S, Menallo G, Mazzola A, et al. Heart valve scaffold fabrication: bioinspired control of macro-scale morphology, mechanics and micro-structure. Biomaterials. 2018;150:25-37.

6. Hobson CM, Amoroso NJ, Amini R, Ungchusri E, Hong Y, D'Amore A, et al. Fabrication of elastomeric scaffolds with curvilinear fibrous structures for heart valve leaflet engineering. J Biomed Mater Res A. 2015;103:3101-6.

7. Usprech J, Chen WL, Simmons CA. Heart valve regeneration: the need for systems approaches. Wiley Interdiscip Rev Syst Biol Med. 2016;8:169-82.

8. Ozaki S, Kawase I, Yamashita H, Uchida S, Takatoh M, Kiyohara N. Midterm outcomes after aortic valve neocuspidization with glutaraldehyde-treated autologous pericardium. J Thorac Cardiovasc Surg. 2018;155:2379-87. 